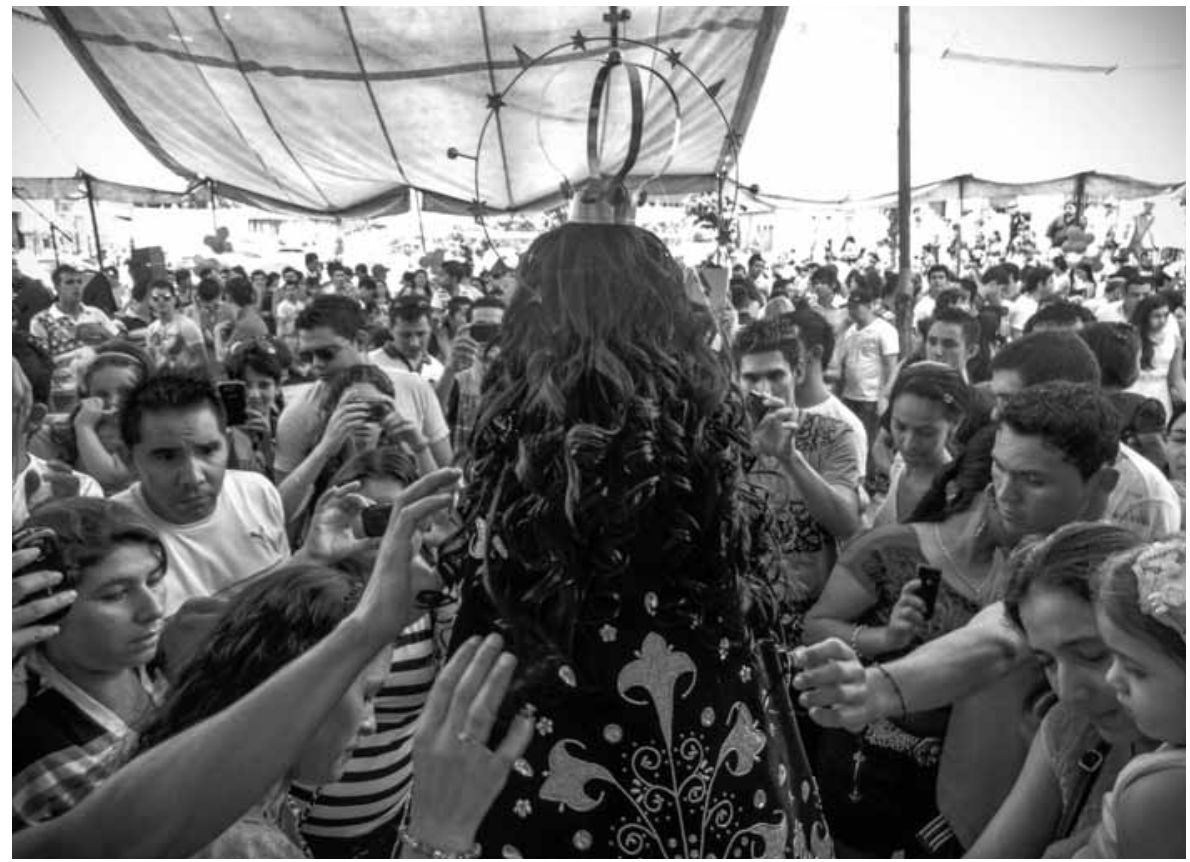

Foto: Porfirio Leonor Ramírez

Adoração de migrantes paraguaios à Virgem de Caacupé na Igreja Nossa Senhora da Paz, no centro de São Paulo, 8 de dezembro de 2013.

\title{
Caacupé Trajetórias de organizações de paraguaios em São Paulo
}

\author{
Porfirio Leonor Ramírez*
}

No domingo de 8 dezembro de 2013, comemorou-se na região central da cidade de São Paulo o dia da Padroeira dos paraguaios, a Virgem de Caacupé, na Igreja Nossa Senhora da Paz, ou Igreja dos Imigrantes como é comumente conhecida. O evento reuniu mais de duas mil pessoas, na sua maioria de nacionalidade paraguaia.

* Graduado em Relações Internacionais pela UNIP; ex-costureiro e co-fundador da Associação Japayke e do Grupo de Danças Acuarela Paraguaya; trabalha no Consulado da Venezuela em São Paulo. 
Conta a lenda que a Virgencita Índia de Caacupé foi promessa de um nativo guarani que estava no mato à procura de alimentos e ficou perdido, quando percebeu que se aproximava um grupo de outra tribo que não aceitava ser evangelizado pelos jesuítas e considerava traiçoeiro aquele que o fazia. $O$ nativo evangelizado, de nome José, fez um pedido à Virgem Imaculada para que o protegesse. No mesmo instante, ela aparece e diz em guarani "ka'aguy kupepe", que traduzido seria "atrás das ervas", em alusão à erva mate que serve de remédios medicinais. A frase em guarani também pode ser entendida como "atrás do mato" ${ }^{1}$. José conseguiu ficar sem ser percebido detrás de um grande tronco. A salvo, ele prometeu que talharia duas imagens da Santa, e assim o fez. Uma foi levada para a Igreja de Tobati, centro da tribo onde os jesuítas cristianizavam os nativos e outra, de menor tamanho, ficou com ele para devoção pessoal. A cidade de Tobati dista 74 quilômetros de Assunção, a capital do Paraguai.

A Basílica da Virgem de Caacupé foi construída com o mesmo nome da Santa. Está na capital do departamento de Cordillera, que tem 282.981 habitantes ${ }^{2}$, segundo a Dirección General de Estadística, Encuestas y Censos $D G E E C$, localizada a 50 quilômetros de Assunção. A cidade é o centro religioso do Paraguai. No mês de dezembro, pátria e igreja se encontram na cidade, traço que ao longo da história paraguaia fez parte do processo de formação da nacionalidade. A quantidade de fiéis em 2013 ultrapassou os 2,5 milhões de pessoas, segundo o jornal paraguaio Última Hora ${ }^{3}$.

A mais de mil e quinhentos quilômetros, na cidade de São Paulo, os devotos paraguaios comemoram este dia com uma missa de ação de graças. Em seguida, um festival de danças tradicionais, grupos musicais ao vivo com instrumentos típicos, como a harpa e o violão, ao ritmo de polcas e guarânias. $O$ domingo de 8 de dezembro de 2013 foi o dia em que o povo vibrou até o final da tarde. A Missa de Ação de Graças e o Festival em homenagem à Santa são organizados pela "Colectividad Paraguaya en São Paulo" ou "Comunidad Paraguaya en São Paulo", grupo formado por paraguaios radicados há muito tempo no Brasil. São pessoas ligadas à igreja, que realizam um trabalho social e religioso junto à Pastoral do Imigrante, hoje denominada Missão Paz.

A missa terminou por volta de uma hora da tarde. A sede da Igreja estava repleta de pessoas. Do lado de fora foi montada uma tenda gigante, com palco, mesas e cadeiras, além das barracas de comidas típicas, bebidas e artesanatos do Paraguai. Com som alto começa a polca da Virgem de Caacupé, que sai da igreja nos ombros de seus fiéis e é levada à frente do palco onde aconteceriam as apresentações. O público presente acompanhou com aplausos, devoção, emoção, alegria e assobios a chegada da Santa, cantando a popular polca paraguaia:

Ya la caravana... de los promeseros...

Asciende la loma...de Caacupé

Campanas de bronce...tocando oraciones

Llaman a los fieles,

Con un canto dulce para el "ñembo'e" [oração em guarani] 
O cheiro das comidas típicas indicava a culinária paraguaia: sopa paraguaia, sopa so'o (com carne), chipaguazú, chipa, empanadas ${ }^{5}$ de vários sabores, churrasco com mandioca e bebidas. Não havia apenas refrigerante e cerveja, também o Tereré estava presente, companheiro dos paraguaios em qualquer lugar do mundo.

A primeira apresentação da tarde foi do Grupo Folclórico Alma Guarani, que levantou o público presente com suas tradicionais danças e encantou com toda a sua elegância. Alma Guarani, como são conhecidos, é formado por paraguaios e descendentes, possui uma trajetória de mais de vinte anos de apresentações, sempre levando o nome do país no mais alto, nos mais importantes festivais de cultura de São Paulo.

Em seguida, apresentou-se o Grupo de Danzas Acuarela Paraguaya, este em seu segundo ano como grupo. As pessoas mantinham o olhar fixo no palco; começaram com uma polca, e logo outra para garantir o aplauso do público e fortalecer o grupo, que desta vez reunia quatro vezes mais integrantes que no ano anterior. O Acuarela Paraguaya é formado majoritariamente por migrantes paraguaios chegados recentemente à cidade, sobretudo após 2010.

Ambos os grupos ofereceram uma tarde de danças com suas vestimentas típicas e coloridas, pés desnudos das dançarinas frente ao olhar apaixonado de seus respectivos companheiros, com sorrisos que pareciam estar conectados aos aplausos e gritos de "viva" do público presente. Contribuíram com a missão de divulgação cultural do Paraguai, cada um deles interpretando e expressando de diversas maneiras a cultura e história do país. A tarde cultural culminou com a apresentação de uma bela harpista que enfeitiçaria o público presente, não só com sua beleza, mas com a delicadeza com que ela executava a harpa, ao som de temas de identidade paraguaia. A festa foi chegando ao fim com a seleção de polcas tocadas ao vivo pelo grupo musical, que levou a todos os presentes a cair no baile popular.

Naquele domingo de dezembro, quando a temperatura chegava aos 35o graus na capital paulista, o público nem parecia preocupado com o calor. Chamava atenção a quantidade de pessoas reunidas naquele lugar, a maior aglutinação de nacionais paraguaios em São Paulo, com a presença de mais de duas mil pessoas. Este foi um dia memorável para muitos paraguaios, para os organizadores, para os grupos e para todas as pessoas que presenciaram o dia da Santa. Esta foi a primeira vez que tantos compatriotas se reuniram num mesmo lugar em São Paulo, vindos de diversos bairros da capital paulista e outras cidades.

Em meio a tantos paraguaios, eu estava presente. Imigrei para São Paulo em 2004. Trabalhei como costureiro durante seis anos, em oficinas de coreanos, peruanos, bolivianos, chilenos, brasileiros e paraguaios. Ajudei a fundar a Associação Japayke e o Grupo de Danças Acuarela Paraguaya. Em 2013, graduei-me em Relações Internacionais pela UNIP em São Paulo e atualmente sou funcionário do Consulado da República Bolivariana da Venezuela em São Paulo. Para este artigo, além das informações que relato como participante direto, foram realizadas entrevistas com outros paraguaios para subsidiar as informações apresentadas. 


\section{Considerações gerais sobre a história e o associativismo dos migrantes paraguaios em São Paulo}

As pessoas naturais de um país, quando migram para outro, seja ele vizinho ou em outro continente, se associam, se organizam, se agrupam em torno de uma identidade comum para reivindicar direitos e, também para a manifestação de suas expressões culturais. A partir disso, iremos debater as diversas organizações de paraguaios na capital paulista.

As associações se fazem necessárias para qualquer comunidade que esteja fora de seu país de origem. Os motivos podem ser diversos, como um problema ou uma necessidade em comum da comunidade. Nesses casos, as associações podem atuar mediando e procurando uma solução, ou, no caso trabalhista, reivindicando direitos e melhorias para os trabalhadores. Apenas de forma organizada, o Estado, que gere as políticas do país de destino, os recebe para escutá-los. Isto não é diferente para os paraguaios em São Paulo, onde existem associações atuando em diferentes frentes. Muitas vezes, elas não conseguem dialogar entre si para reivindicar uma necessidade maior da Comunidade em seu conjunto, de modo a aumentar as chances de o Estado brasileiro, em todas suas esferas, acatar suas demandas.

Podemos pensar a migração paraguaia para São Paulo em três momentos diferentes: o primeiro, durante a longa ditadura de Alfredo Stroesnner (19541989), marcado pela vinda de profissionais qualificados, artistas e os perseguidos que fugiram procurando um novo horizonte no Brasil, mais especificamente na cidade de São Paulo, talvez porque Buenos Aires não fosse o melhor destino para aquele momento, levando em consideração a quantidade de paraguaios que lá moravam na década de 1970; o segundo momento refere-se à década de 1990, após a ditadura militar no Paraguai, quando seus cidadãos começaram a experimentar a democracia, inédita naquele país, e uma nova etapa de integração regional que foi o Mercado Comum do Sul - MERCOSUL; o terceiro acontece a partir da virada do século e se estende até a presente data, quando as crises na Argentina e na Espanha passaram a tornar São Paulo um destino mais atrativo aos paraguaios. Três momentos diferentes em que o Brasil recebeu imigrantes paraguaios que, por motivos diferentes, saíram de seu país para virem a São Paulo tentar a sorte.

\section{Ditadura, repressão e migração}

Os primeiros paraguaios que chegaram a São Paulo, fugindo da ditadura militar do país, não se importavam que a situação política por aqui não fosse muito diferente. São Paulo ainda seria melhor do que Buenos Aires, por exemplo, 
onde a comunidade estava em alta, e era mais fácil ser reconhecido, no caso de ser militante político ou familiar de algum procurado pelo regime militar daquele país ${ }^{6}$. Os países sul-americanos trabalharam em conjunto na Operação Condor ${ }^{7}$ para a troca de informações, captura e troca de prisioneiros políticos, bem como perseguição e assassinato de inimigos políticos no exterior, muitas vezes no próprio exílio. Também chegaram profissionais para representar os interesses do regime: vieram através de representações diplomáticas, como representantes de empresas estatais, além de gerentes de algumas empresas dos donos do poder no Paraguai.

Além disso, nesta primeira migração existia o medo que causava o Estatuto do Estrangeiro de 1980. O documento promulgado na ditadura militar brasileira, vigente até os dias de hoje, proíbe a reunião ou organização de estrangeiros com caráter político, considerando tal prática como agressão ao Estado. O Estatuto foi formulado sob a égide da doutrina de segurança nacional, apoiada pelos Estados Unidos e aplicada pelos regimes ditatoriais que governavam a região, no contexto de Guerra Fria, em que estrangeiros podiam ser vistos como inimigos infiltrados no campo de luta entre os dois lados da cortina de ferro.

Neste cenário de desconfiança, a Comunidade em São Paulo encontrava-se na igreja, no campo de futebol ou no Consulado, quando o assunto era trâmite burocrático e não se estava em dívida com a justiça paraguaia. Para alguns veteranos ${ }^{8}$, o Campo de Marte, na zona norte da cidade, era um lugar especial para o encontro de paraguaios. Pelo exposto, nota-se que o perfil do paraguaio que veio nesse período era mais qualificado, alguns trabalhavam em empresas estatais ou privadas, outros deixaram o país por motivos políticos. O convite para jogar futebol entre paraguaios acontecia depois da missa, realizada na Pastoral dos Imigrantes, e no campo de futebol acontecia o inverso - o convite para frequentar a igreja.

Os encontros de futebol entre paraguaios eram realizados para a confraternização, para matar a saudade de beber um tereré, falar em guarani e compartilhar as últimas notícias do Paraguai. Informações eram trazidas por paraguaios que vinham fazer compras em São Paulo ou pelos jornais trazidos pelos motoristas das empresas que faziam o trajeto de Assunção à capital paulista.

A formação de algum comitê ou comissão entre os cidadãos se dava em situações como comemoração de festas pátrias, festas católicas ${ }^{9}$ ou datas importantes para o país. Também eram organizados torneios beneficentes para colaborar com algum paraguaio de escasso recurso que tivesse chegado a São Paulo ou que estivesse precisando de ajuda para solucionar algum problema familiar de emergência. Este tipo de colaboração para ajudar o próximo, organizada através de torneios de futebol ou de sorteios de prêmios doados é muito comum entre paraguaios. 


\section{Democracia, Integração Regional e Associativismo}

O segundo período, ao longo dos anos 1990, parece ter sido marcado por pouca migração paraguaia para São Paulo. Este fluxo só teria crescido substancialmente na segunda metade dos anos 2000. Esta migração aconteceu num período em que o Paraguai estava vivenciando uma nova etapa, a abertura política que aconteceu depois da derrubada do Stroessner com um novo golpe militar em fevereiro de 1989, que na sequência chamaria eleições presidenciais. A abertura política deu a possibilidade aos paraguaios de participarem de eleições diretas e da definição de uma nova Carta Magna, em 1991. A democracia voltava à região. Neste cenário foi assinado o Tratado de Asunción que deu início ao Mercado Comum do Sul - Mercosul ${ }^{10}$ em 1991. A união aduaneira dos países da Bacia do Prata deu um maior dinamismo ao intercâmbio comercial entre os Estados parte e o trânsito de pessoas aumentou com as novas leis migratórias que facilitavam o ingresso de nacionais entre os países que compunham o bloco regional.

Em relação ao associativismo, a prática do esporte e a participação em atividades da Pastoral constituíam instâncias catalizadoras da organização de paraguaios na cidade. Assim como o esporte foi ferramenta que servia aos que idealizavam criar uma associação, as missas de domingo ajudavam a organizar a comunidade paraguaia.

A Pastoral do Imigrante colaborou para que a associação de paraguaios se concretizasse, sem deixar de pautar os aspectos relacionadas a seus interesses, como a organização das festas anuais da Virgem de Caacupé, além das pequenas atividades organizadas ao longo do ano, como novenas, para que mantivessem a aproximação desses migrantes à paróquia. Também vale destacar o trabalho social que a Pastoral desempenhou na recepção e acompanhamento de imigrantes perseguidos, fugitivos e aqueles que chegaram em busca de melhorar sua situação. No entanto, pode-se indagar sobre esta forma de aproximação com os migrantes e questionar a importância da auto-organização deles no sentido de se articularem para reivindicar direitos no país.

As características destas duas etapas da migração paraguaia em São Paulo são a organização através do esporte, com torneios de futebol em lugares mais frequentados pelos nacionais, as festas de independência e a comemoração da Virgem de Caacupé, em dezembro de todos os anos.

\section{O surgimento de um grupo folclórico}

Entre os fatores que dificultavam o associativismo, talvez um deles tenha a ver com a qualificação dos migrantes. Na primeira etapa eram profissionais de alto escalão, como doutores de clínicas famosas, contadores, banqueiros e representantes do regime. Então, os interesses eram outros. Por exemplo, a promoção cultural do país em suas datas pátrias e apoio com recursos para a 
realização do dia da Virgem em cada final de ano. Foi neste período que surgiu o Grupo Folclórico Alma Guarani, que possui uma trajetória de mais de vinte anos, fundado nos anos 1990, a partir da necessidade da comunidade paraguaia fazerse representar na Festa das Nações, promovida pela Pastoral do Imigrante. Um dos principais objetivos do grupo era a divulgação da cultura paraguaia através da dança, valorização das tradições guaranis, inclusão social e a integração. 0 grupo carrega uma bagagem de apresentações na capital paulista.

Os paraguaios do segundo momento apresentavam outros tipos de problemas para a sua inserção na cidade; sofriam o peso da migração não qualificada. Essas pessoas tinham outro perfil: eram de famílias mais humildes, chegaram a São Paulo para procurar emprego, que na maior parte das vezes era em oficinas de costura dominadas por coreanos, onde se trabalhava mais de 15 horas diárias de segunda-feira à sexta-feira e, aos sábados, até o meio-dia.

\section{O novo fluxo migratório e a atualidade}

Dos três períodos citados, para debater a forma de organização dos paraguaios em São Paulo, o que mais chama a atenção é o último. São novos fluxos de migrantes que chegam diariamente e de forma crescente nesta primeira década dos anos 2000. Em sua maioria, são jovens entre 17 e 29 anos que buscam oportunidades de emprego e uma vida mais digna.

A forma de organização para reivindicar uma pauta que atendesse às necessidades dos primeiros imigrantes paraguaios deu-se através dos pequenos encontros nos campos de futebol, nas festas religiosas e comemorações nacionais paraguaias. Nesse momento, havia outros desafios postos aos migrantes. Não existia a visibilidade atual de cenário de exploração do trabalho.

$\mathrm{O}$ crescimento da economia brasileira e a demanda por mão de obra foram fatores responsáveis para o Brasil ser atraente como destino migratório, sem contar com problemas locais que também ajudaram a impulsionar a decisão de migrar. Também podem ser considerados a crise na Argentina em 2002 e a recessão econômica na Espanha a partir 2008. O novo contingente de imigrantes que começou a chegar à cidade de São Paulo nos últimos dez anos marca uma diferença quando comparado com os anteriores, seja na forma de organização na cidade, nas reivindicações de direitos sociais, ou mesmo pelas diferenças geracionais e de qualificação profissional.

\section{Surgem novas associações}

No bairro do Bom Retiro, destino privilegiado dos migrantes que vieram para trabalhar em oficinas de costura, surgiu uma tentativa de Associação independente da Pastoral, em torno de um restaurante paraguaio. Historicamente, o bairro se caracteriza por ser receptor de imigrantes de várias nacionalidades 
de todo o mundo. Nos últimos anos, o bairro recebeu uma quantidade visível de paraguaios, que iria aumentar com o passar do tempo. Com a estratégia de iniciar a organização de paraguaios dessa nova geração, que vive nos arredores do Bom Retiro, foi formada uma Comissão no bairro para discutir os problemas da comunidade, como acidentes de trabalho, necessidades básicas para sobreviver, assessoria para os trâmites de documentação, entre outros. A estratégia para agregar jovens migrantes a fim de reivindicar seus direitos na cidade foi, inicialmente, através da organização de eventos esportivos e de lazer, como bailes tropicais. De modo geral, as iniciativas com cunho e objetivo de organização política tendem a ser malvistas pela comunidade. Sendo assim, para que se conseguisse mobilizar os migrantes em torno de pautas que lhes são caras, essas estratégias foram adotadas.

Tendo em vista o perfil jovem e de recém-chegados, começou-se a organizar torneios de futebol com bailes tropicais como a cumbia e outros ritmos, que é a maneira mais fácil de chamar a atenção da juventude que estava chegando e se apropriando do bairro aos poucos.

De acordo com J.K ${ }^{11}, 32$ anos, que chegou a São Paulo no final da década de 1990 e participou da iniciativa, tratava-se de um projeto ousado de Associação, que previa um número mínimo de sócios e até uma cooperativa. No entanto, a desconfiança entre os membros da iniciativa levou ao fim do grupo, com acusações de "pro-bolsillo"12 entre os membros. O projeto de associação acabou, mas continuou como iniciativa privada.

Em 2008, a Pastoral chamou as principais lideranças paraguaias para criarem outra associação. A iniciativa se dividiu em dois grupos, o primeiro se intitulou Comunidad Paraguaya en São Paulo, ou Coletividad Paraguaya en São Paulo. Trata-se do grupo que se encarrega das datas comemorativas nacionais e religiosas do Paraguai, próxima dos interesses da Pastoral. O segundo grupo iria se constituir em 2010 como Associação Japayke.

A denúncia no Jornal Abc Color ${ }^{13}$ por parte de cidadãos paraguaios de que seus conterrâneos estavam em situação análoga a de trabalho escravo lançou o primeiro alerta para a necessidade de uma Associação. Tratava-se de lutar pelos direitos das pessoas que trabalham mais de 14 horas por dia nas pequenas oficinas de costura de bairros como Bom Retiro, Brás, Casa Verde, Vila Medeiros e Vila Any, em Guarulhos, para citar algumas localidades.

Desde minha chegada em São Paulo, tive muitas dificuldades, como qualquer outro jovem imigrante no período. A importância da organização é fundamental para qualquer comunidade fora de seu país de origem. Só acreditei nisso quando conheci as pessoas que tinham a mesma ideia, a de se organizar para tentar mudar essa realidade.

Em abril de 2010, ajudei a fundar a Associação de Integração Paraguai Brasil Japayke, que em guarani significa "vamos despertar" ou "despertar-se". Ela se reivindica como política ao mostrar-se comprometida com as necessidades dos paraguaios e, também, visa promover uma imagem positiva do Paraguai 
através de iniciativas culturais. A Associação Japayke é formada por paraguaios e descendentes da primeira, segunda e terceira migração.

A Japayke promoveu várias reuniões com representantes do governo local e do Paraguai, sindicatos, movimentos sociais e sociedade civil para apresentar a problemática dos paraguaios, cuja migração para São Paulo nesse período estava em alta. A primeira reunião foi realizada com o governo paraguaio, representado pelo então Ministro de Relações Exteriores Hector Lacognata ${ }^{14}$. Participaram vários paraguaios de distintos bairros da cidade e de Guarulhos, buscou-se informá-los da situação em que vivem os migrantes. Além disso, foram discutidos temas diversos, como apoio através do governo, repatriação, direito ao voto e o melhor atendimento no Consulado. Segundo alguns veteranos, apenas atualmente há conversas com o Cônsul, anteriormente o acesso era dificultado.

Paraguaios donos de oficinas de costura e até costureiros que trabalhavam com coreanos faziam denúncias à Associação. Havia relatos dos mais variados, como atraso de pagamento de salários, visita do sindicato da área e acusação de "roubar posto de trabalho de brasileiros", atraso de pagamentos de serviços por mais de 30 dias por parte dos coreanos, etc.

A Japayke fazia a intermediação das questões mais pontuais. Participou de vários seminários contra trabalho escravo, sempre levando depoimentos de pessoas das oficinas de costura, e apresentava propostas. A Associação buscou sensibilizar a discussão pública para a questão dos trabalhadores imigrantes, pois se trata de um fenômeno pouco conhecido e relativamente recente.

Durante o seminário "Vida e Trabalho decente para paraguaios $e$ brasileiros" promovido pela Central Sindical das Américas e suas filias brasileiras e paraguaias, o Presidente da Japayke, Humberto Jara, alertou que o primeiro passo é a aproximação aos trabalhadores que deixam o Paraguai, é necessário conhecê-los. Continuou dizendo que "estamos falando de pessoas que pouco conhecem sobre seus direitos, que deixam a enxada para vir costurar no Brasil. Antes de cobrarmos que se sindicalizem, que se registrem, devemos conversar para conhecer a realidade na qual vivem. Caso apenas criminalizemos os paraguaios que compram máquinas para produzir para grandes redes, que são tão miseráveis quanto os outros que costuram, teremos muito mais gente na cracolândia"15. Com declarações deste tipo, responsabilizava as grandes grifes, que obtêm os maiores lucros da cadeia produtiva do vestuário.

As bandeiras de luta tinham várias frentes: o trabalho descente no Brasil; o direito ao voto no Paraguai e no Brasil; criação de um espaço para a Casa Paraguaia, que seria um lugar de encontro dos migrantes para exporem sua cultura, sua música e sua arte.

Podemos dizer que a Japayke talvez tenha sido a Associação que mais tentou organizar os paraguaios através de iniciativas políticas ${ }^{16}$ e culturais, muitas das quais foram realizadas no interior do estado em parceria com a Central única dos Trabalhadores - CUT. 


\section{Acuarela Paraguaya, a cara da migração paraguaia em São Paulo}

Foi depois de encontros com debates que conseguimos formar um grupo folclórico paralelo à Japayke. Durante a 5a Marcha dos Imigrantes no centro de São Paulo, um grupo de jovens que acompanhava a associação constatou a falta de um grupo cultural paraguaio que apresentasse algum canto, dança ou poesia no final da marcha, já que todas as demais comunidades estavam representadas.

Com a ideia em mente dos jovens migrantes, além da oportunidade surgida de concorrer como um projeto de uma política pública cultural da prefeitura de São Paulo, iniciou-se o Grupo de Danza Acuarela Paraguaya, beneficiado pelo Programa VAI - Valorização às Iniciativas Culturais. $\mathrm{O}$ apoio público propiciou as ferramentas de que precisávamos para começarmos a desenvolver o trabalho cultural, social e de conscientização dos jovens que chegavam para tomarem parte do projeto. A meta traçada para 2014 é a de levarmos a dança paraguaia pela periferia da cidade de São Paulo, com 16 apresentações.

Através da dança, com o Acuarela Paraguaya, tentamos construir um conceito de cultura e de política comprometido com os jovens paraguaios e com a realidade em que vivem. O Grupo incentiva a participação em cursos de português, cursos de informática, em debates sobre a história e a realidade do Paraguai; procura resolver questões pessoais, prega a solidariedade entre todos visando criar uma identidade de família. As iniciativas culturais que o Acuarela empreende de dança e teatro sempre tentam resgatar a história através dos passos no ritmo da polca ${ }^{17}$, propondo o respeito às diferenças de gênero, de nacionalidade e promovendo a integração entre as diversas comunidades que residem em São Paulo. O Grupo também participa dos movimentos que atuam na defesa dos direitos dos imigrantes e apoia bandeiras como a do direito ao voto do imigrante.

\section{"Um pedacinho do Paraguai na zona oeste de São Paulo"18}

O jornal O Estado de São Paulo dedicou uma página impressa para analisar um espaço muito frequentado pelos paraguaios, a Praça Nicolau de Moraes Barros. Ela está localizada na Barra Funda, já esteve abandonada e cheia de mato, hoje reúne centenas de pessoas todos os finais de semana. A praça é chamada pelos paraguaios "Ybycu'i", que significa areia, já os brasileiros a chamam de Areião.

Os paraguaios que a frequentam são os recém-chegados, que todos os finais de semana vão jogar bola e levar as crianças para brincar. Neste espaço, a Japayke organizou o Bicentenário ${ }^{19}$ da Independência do Paraguai, que reuniu quase mil pessoas, num festival cultural com danças e comidas típicas, apresentações de artistas paraguaios de aqui e acolá. 0 evento foi realizado pela Associação Japayke em conjunto com o poder público e as centrais sindicais. 
Em 2012, a Acuarela Paraguaya realizou duas atividades. A praça é um grande anseio de muitos migrantes, eles a chamam de praça dos paraguaios, pela ocupação de todos os finais de semana e da identidade que foi ganhando o lugar. A língua guarani e as rodas de tereré predominam nesse espaço. Alguns dos migrantes buscam transformar a praça em um ponto de referência para a comunidade, a exemplo do que ocorreu com a Praça Kantuta ou com a Rua Coimbra que se tornaram referência para os bolivianos residentes na RMSP.

É através dessas iniciativas que se quer mudar a imagem negativa que se tem do Paraguai. Muitas vezes, cultivada pela mídia local, a imagem do Paraguai é frequentemente ligada ao contrabando de produtos, de armas e tráfico de drogas. Sempre o ruim é associado ao Paraguai, mesmo com piadas sem graça tipo "é do Paraguai", em alusão aos produtos falsificados contrabandeados por brasileiros, que lucram comercializando-os. Muitos utilizam esta expressão como forma de menosprezar o país vizinho, com eco na mídia brasileira.

Para fazer frente a isso, surgiu o Núcleo Cultural Paraguai Teeté ${ }^{20}$, que significa "Paraguai de Verdade", para mostrar o outro lado do Paraguai que aqui não é conhecido. Formado por jornalistas, professores, intelectuais e simpatizantes mantém um blog em português, o qual mostra aos leitores as notícias positivas do Paraguai; o que acontece nas áreas da cultura, esporte, culinária, tecnologia, educação, literatura, bem como contesta, com cartas abertas e abaixo-assinados, qualquer publicação sem fundamento que desrespeite o Paraguai e seus nacionais.

\section{Conclusão}

Através deste texto tentamos criar um debate, partindo da comemoração do Santo Ara (Dia Santo da Virgencita de Caacupé), abordando vários assuntos para o leitor atinentes às dificuldades dos paraguaios em se organizarem na capital paulista. No dia da Santa, ficou evidente a religiosidade do paraguaio e como a Virgem de Caacupé reúne seus fiéis em grande número. De modo geral, observamos que o imigrante paraguaio se aglutina e se mobiliza em torno das atividades religiosas.

Historiamos brevemente a migração paraguaia para a capital paulista desde a segunda metade do século passado. Mostramos os motivos dessa migração em períodos diferentes e sugerimos uma divisão em três momentos: o da ditadura; o da abertura democrática e o do momento atual, este iniciado na virada do século.

Vimos também que o esforço de associativismo na migração paraguaia ganhou ênfase a partir dos anos 2000, quando a comunidade cresceu rapidamente. Talvez porque apareceram os problemas, necessidades que precisavam ser resolvidas através de uma associação que pudesse prestar assessoria perante 
qualquer situação. Houve tentativas independentes, com mediação da Pastoral, que tiveram sucesso atendendo a seus interesses, enquanto outras não prosperaram.

Uma das dificuldades maiores do atual fluxo migratório diz respeito à visão sobre a organização. A palavra política, em todos os seus sentidos, causa desconfiança. Podemos pensar que talvez um dos erros das lideranças paraguaias seja desqualificar a política em toda sua essência e confundi-la com a política partidária. A meu ver, a política deve ser entendida como a ação de se fazer o bem comum, através de organizações, mediando as necessidades e procurando soluções através de negociações. Para a maioria dos paraguaios, porém, política significa simplesmente politicagem, corrupção e dinheiro fácil. Trata-se de um senso comum muito arraigado entre os paraguaios. A corrupção apoderou-se da política paraguaia em todas as esferas do poder, por isso talvez esta visão seja predominante. Por exemplo, quando se tem uma iniciativa para arrecadar dinheiro para uma pessoa que passa por dificuldades, todos colaboram. Mas, se os fins forem para arrecadar recursos para a fundação de uma associação, a adesão é mínima e são grandes as dificuldades para se seguir adiante.

Acredito que isso aconteça por causa das decepções sofridas pelo povo paraguaio, que passou por guerras, ditaduras e uma democracia que até a atualidade possui instituições fracas. Além disso, uma elite agrária governa o país e se apodera de toda a riqueza produzida. Esses são fatores fundamentais que servem para auxiliar na explicação da migração para países vizinhos.

Os festivais culturais propiciaram o surgimento de grupos de danças típicas paraguaias, que ajudam a manter as tradições por meio da arte e cumprem a função de difundir a cultura nos diversos lugares da cidade. Atualmente só existem dois grupos: um com mais de vinte anos de bagagem, e outro com dois anos, mas ambos com muitas responsabilidades que vão além da divulgação cultural, tal como a inserção dos jovens paraguaios e latinos, e a valorização das tradições paraguaias.

Para chegar a grandes resultados, faz-se necessário um diálogo amplo dentro da comunidade, entre as associações, grupos folclóricos, esportivos e pessoas, a fim de acertar uma agenda comum, com objetivos claros, que beneficie a todos os paraguaios que residem na cidade de São Paulo e em outros municípios da Região Metropolitana. Pode ser retomada, por exemplo, a iniciativa da Associação Japayke de conversar com as autoridades brasileiras e paraguaias, com pautas concretas, como a repatriação organizada, ou mesmo mediar uma negociação para adquirir um espaço para a Casa ou Praça Paraguaia, como ocorre em outras grandes cidades do mundo onde residem imigrantes paraguaios. Seria uma vitória termos um espaço onde pudéssemos expor toda nossa cultura e tradição, que prestasse assistência jurídica e serviços de orientação aos compatriotas para trâmites de documentos, além de se constituir num lugar de encontro e ponto de referência para os paraguaios. 


\section{Notas}

1 - EL ORIGEN DE CAACUPE Y DE LA ADVOCACIÓN. Ver mais em: <http://forosdelavirgen. org/415/nuestra-senora-de-los-milagros-de-caacupe-paraguay-8-de-diciembre/>. Acesso em: 25 jun. 2014.

2 - 3er. DEPARTAMENTO DE LA CORDILLERA. Ver mais em Anuário DGEEC, 2012: <http://www. dgeec.gov.py/Publicaciones/Biblioteca/anuario2012/anuario\%202012.pdf>. Acesso em: 27 maio 2014.

3 - Ver mais em: Unos 2.500 .000 peregrinos visitaron a la Virgen Serrana: <http://www. ultimahora.com/unos-2500000-peregrinos-visitaron-la-virgen-serrana-n748020.html>. Acesso em: 27 maio 2014.

4 - Ver mais da Música e letra em: <http://www.dparaguay.com/2013/12/virgencita-decaacupe-letra-y-musica.html>. Acesso em: 25 jun. 2014.

5 - A base da culinária paraguaia é o milho. A Sopa Paraguaia é uma torta salgada que leva farinha de milho, ovos, queijo, azeite e sal. Para fazer o chipaguazú é a mesma receita que a Sopa, só trocar a farinha pelo milho moído fresco. A chipa seria o pão paraguaio, que leva farinha de mandioca, sal, ovos, queijo, erva doce e margarina. As empanadas mais populares são a de carne, frango e presunto com queijo. As empanadas têm uma massa fina tipo pastel brasileiro com recheio de carne bem condimentado, valendo para as de frango e presunto com queijo.

6 - No Paraguai, ao contrário do que se pensa, houve resistências nos moldes de revolução armada no campo e resistências urbanas. Foram organizadas por partidos, profissionais da educação, militares, intelectuais, Ligas Agrárias e estudantes de diversas áreas. Estavam aglutinadas em organizações dentro do país com tentativas insurgentes, que não tiveram sucesso, contra o regime de Stroessner. Também foram organizadas expedições desde o exterior por militantes de organizações que fugiram, por um curto período de tempo, e pelos exilados que queriam retornar. Ver mais em: LA RESISTENCIA ARMADA AL STRONISMO: PANORAMA GENERAL <http://www.novapolis.pyglobal.com/pdf/novapolis8.pdf>. Acesso em: 27 maio 2014.

7 - Ver mais em Operação Condor: Ditaduras se uniram para perseguir adversários: <http:// educacao.uol.com.br/disciplinas/historia-brasil/operacao-condor-ditaduras-se-uniram-paraperseguir-adversarios.htm>. Acesso em: 20 jun. 2014.

8 - Denominação que vai ser dada no texto aos paraguaios que moram em São Paulo há mais de 20 anos.

9 - Segundo o Instituto Brasileiro de Geografia e Estatística - IBGE - o Censo de 2010 diz que $76,4 \%$ dos paraguaios em São Paulo são Católicos; 8,5 sem religião; 2,5\% ateus; os demais $12,7 \%$ estão divididos em diferentes religiões e igrejas, a maioria evangélicas.

10 - MERCOSUL. Ver mais em: <http://www.mercosul.gov.br/>. Acesso em: 27 maio 2014.

11 - Nome fictício do entrevistado.

12 - Frase usada no Paraguai para referir-se às Associações que atuam em favor próprio, auferindo lucros pessoais.

13 - Los inmigrantes paraguayos viven en preocupante condición en São Paulo. Ver mais em: <www.abc.com.py/edicion-impresa/economia/los-inmigrantes-paraguayos-viven-enpreocupante-condicion-en-so-paulo-1108353.html>. Acesso em: 11 jul. 2014.

14 - Lacognata se reunirá con compatriotas que residen en San Pablo. Ver mais em: <www. nanduti.com.py/v1/noticias-mas.php?id=12890\&cat=Nacionales>. Acesso em: 25 jun. 2014. 
15 - Vida e Trabalho decente para paraguaios e brasileiros. Ver mais em: <www.cut.org.br/ destaques/19889/vida-e-trabalho-decente-para-paraguaios-e-brasileiros-sp>. Acesso em: 27 maio 2014.

16 - Entidade paraguaia debate realidade do migrante no país. Ver mais em: <http://www. vermelho.org.br/noticia/182437-7>. Acesso em: 20 jun. 2014.

17 - Uma das músicas que Acuarela Paraguaya apresenta nos eventos se chama "Campamento Cerro León" que foi o Quartel de Solano López, retratando a despedida dos soldados para ir às batalhas da Guerra do Paraguai.

18 - Título de uma matéria no Jornal Estadão. Ver mais em: <www.sao-paulo.estadao.com. $\mathrm{br} /$ noticias/geral,um-pedacinho-do-paraguai-na-zona-oeste-de-sao-paulo-imp-,1096124>. Acesso em: 20 jun. 2014.

19 - Bicentenário da República do Paraguai. Ver mais em: <http://www.cut.org.br/ acontece/20748/vida-e-trabalho-decente-para-imigrantes-no-paraguai-e-no-brasil-sp>. Acesso em: 27 maio 2014.

20 - Blog do Paraguai Teeté: <www.paraguaiteete.wordpress.com>. Acesso em: 25 jun. 2014.

\title{
RESUMO
}

Este artigo procura debater a migração paraguaia na Região Metropolitana de São Paulo do ponto de vista de suas organizações, a partir de uma perspectiva autocrítica das associações dos paraguaios residentes em São Paulo. Partindo do evento do "Santo Ara" (Dia da Santa, "La Virgencita de Caacupé"), foram problematizadas as dificuldades dos paraguaios para se organizarem desde sua chegada à cidade, o perfil dos migrantes e a sua inserção na sociedade paulista. A história da migração paraguaia na capital paulista desde a segunda metade do século passado foi separada em três momentos: a ditadura Stroessner, a abertura democrática no Paraguai e os fluxos mais recentes a partir dos anos 2000. Procurou-se aprofundar o debate sobre o papel das associações e suas reivindicações, das manifestações culturais dos grupos folclóricos e os desafios que devem ser superados de maneira conjunta.

Palavras-chave: paraguaios; associações; religiosidade.

\begin{abstract}
This article seeks to discuss the Paraguayan migration to the Metropolitan Region of São Paulo in terms of their organization, based on a self-critical perspective from the Paraguayan associations in São Paulo. Based on the "Ara Santo" (Holy Day) event, the paper discusses the difficulties of Paraguayans to organize themselves since their arrival, the migrants' profile and their integration in the paulista society. The history of Paraguayan migration to São Paulo, since the second half of the last century, was divided into three stages: the Stroessner dictatorship, the democratic opening in Paraguay and the most recent flows from the 2000s. We sought to deepen the debate on the role of associations and their claims, the cultural manifestations of folk groups and the challenges that must be overcome jointly.
\end{abstract}

Keywords: paraguayans; associations; religiosity. 


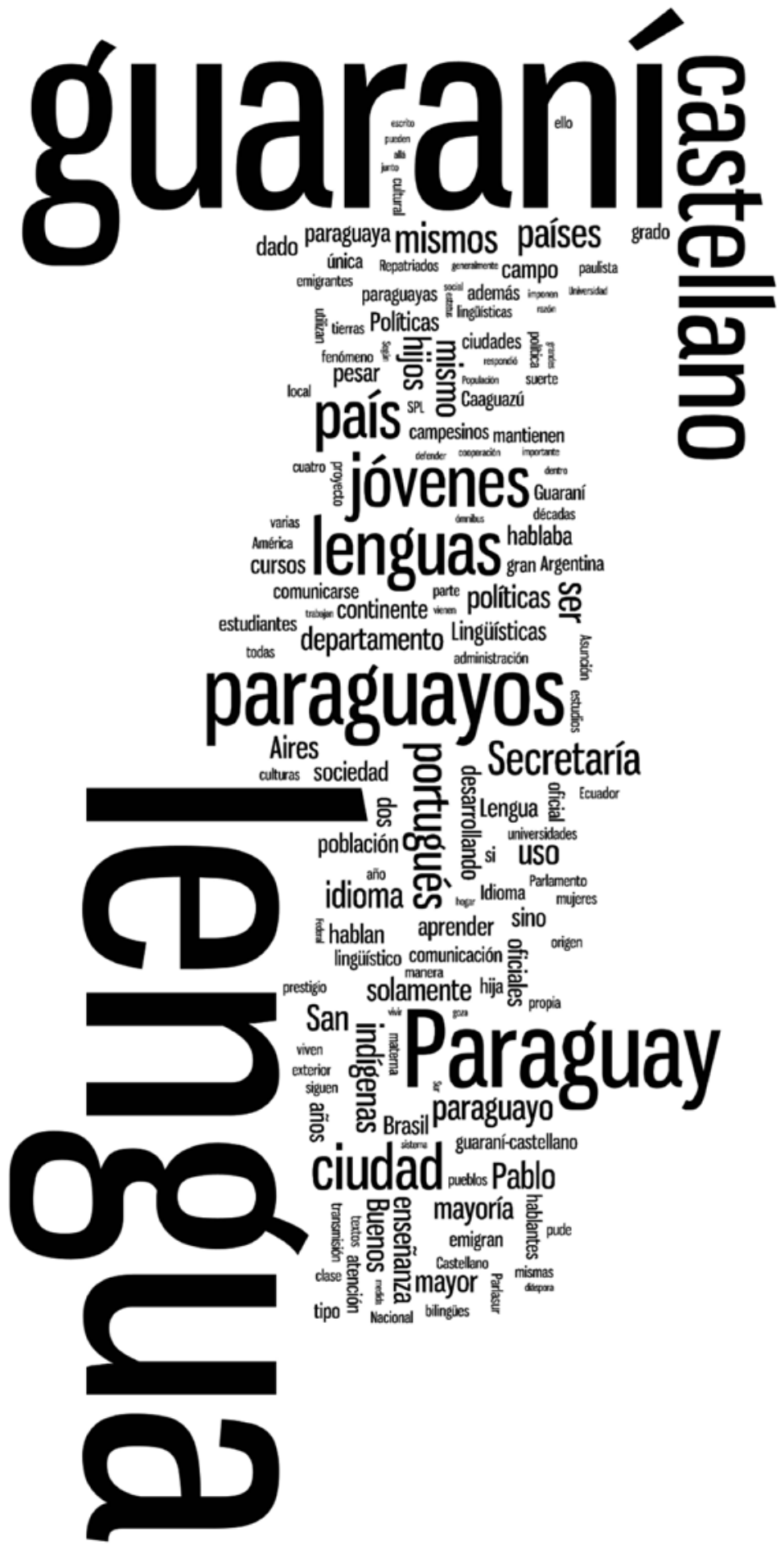


